\title{
INVESTIGATIONS OF THE WORKING PROCESS IN A DUAL-FUEL LOW-EMISSION COMBUSTION CHAMBER FOR AN FPSO GAS TURBINE ENGINE
}

\author{
Serhiy Serbin ${ }^{1}$ \\ Badri Diasamidze ${ }^{1}$ \\ Marek Dzida ${ }^{2}$ \\ ${ }^{1}$ Admiral Makarov National University of Shipbuilding, Ukraine \\ ${ }^{2}$ Gdańsk University of Technology, Poland
}

\begin{abstract}
This investigation is devoted to an analysis of the working process in a dual-fuel low-emission combustion chamber for a floating vessel's gas turbine. The low-emission gas turbine combustion chamber with partial pre-mixing of fuel and air inside the outer and inner radial-axial swirlers was chosen as the object of research. When modelling processes in a dualflow low-emission gas turbine combustion chamber, a generalized method is used, based on the numerical solution of the system of conservation and transport equations for a multi-component chemically reactive turbulent system, taking into consideration nitrogen oxides formation. The Eddy-Dissipation-Concept model, which incorporates Arrhenius chemical kinetics in a turbulent flame, and the Discrete Phase Model describing the interfacial interaction are used in the investigation. The obtained results confirmed the possibility of organizing efficient combustion of distillate liquid fuel in a low-emission gas turbine combustion chamber operating on the principle of partial preliminary formation of a fuel-air mixture. Comparison of four methods of liquid fuel supply to the channels of radial-axial swirlers (centrifugal, axial, combined, and radial) revealed the advantages of the radial supply method, which are manifested in a decrease in the overall temperature field non-uniformity at the outlet and a decrease in nitrogen oxides emissions. The calculated concentrations of nitrogen oxides and carbon monoxide at the flame tube outlet for the radial method of fuel supply are 32 and $9.1 \mathrm{ppm}$, respectively. The results can be useful for further modification and improvement of the characteristics of dual-fuel gas turbine combustion chambers operating with both gaseous and liquid fuels.
\end{abstract}

Keywords: gas turbine engine; dual-fuel combustion; combustion chamber; liquid fuel

\section{INTRODUCTION}

Increased production in deep-sea and remote terrestrial areas has led to an increase in the number of Floating Production, Storage, and Offloading (FPSO) vessels. By the end of 2018, there were 183 FPSO vessels operating in the offshore fleet, with 55 more expected to be built by 2022 [1]. One of the main factors that ensure the efficient operation of the first link in the logistics chain of production (transportation supply of offshore oil and gas) is indicators of power plant's energy efficiency. The composition and characteristics of the installations of such offshore infrastructure vary widely. The main drive engines for power generators and process compressors are gas turbine engines and medium-speed diesel engines.

FPSO power plants that are commonly used are gas turbines and combined plants. So, on board the FPSO Global Producer III, the power plant consists of two gas turbine units with a total capacity of $32 \mathrm{MW}$ and a utilization facility that provides heat to all consumers associated with the technological cycle [2]. The main power plant of the FPSO Armada Olombendo has three gas turbine engines of $21 \mathrm{MW}$ each [3]. The combined power plant of the FPSO Dhirubhai-1 has three gas turbogenerators with a capacity of $4 \mathrm{MW}$ and two main boilers for the operation of steam turbogenerators with a total capacity of 17 MW [4]. Several 
works are devoted to the improvement of power plants that can be used on FPSOs [5-7].

One of the possible ways to increase the manoeuvrability, flexibility, and efficiency of gas turbine power modules for a FPSO unit is the use of dual-fuel combustion in the combustion chamber. The main problem in developing dual-fuel combustion chambers is to ensure the minimal emission of nitrogen oxides when working on liquid fuel. Compared to gaseous fuels, the emission of nitrogen oxides can significantly increase due to deterioration of the fuelair mixture conditions, an increase in the flame emissivity, and increases in combustion length and the working fluid's residence time in high-temperature zones. Very often, steam or water is supplied to the primary combustion chamber's zone to suppress the formation of nitrogen oxides; however, this reduces the reliability of the power plant due to the presence of additional systems and raises the cost of maintenance. Therefore, the development of gas turbine dual-fuel combustion chambers that provide the necessary emissions of nitrogen oxides without steam or water injection is an urgent task.

The problem of improving the emission performance in combustion devices of gas turbine engines was considered in [8-10]. It should be noted that many researchers $[11,12]$ indicate that improving the quality of mixture formation, turbulent interaction under conditions of strongly swirling flows, and increasing the quality of liquid fuel atomization lead to the homogenization of mixtures, more active burning of fuels with different phase compositions, and, as a result, a reduction in nitrogen oxide emissions.

Despite a large amount of scientific research in the field of low-emission combustion chambers, the methodological and technical aspects of solving the problem of development of dual-fuel combustion chambers for an FPSO power system have not been sufficiently developed to date. It should be noted that most investigations of dual-fuel combustion chambers have been done exclusively by experimental methods, while only a small number of researchers [13-15] have used methods of computational fluid dynamics (CFD). In our opinion, research in this area will be relevant and will be able to significantly increase the efficiency of dual-fuel chamber workflow as well as expand the limits of flame propagation in flame tubes and the range of sustainable and ecologically clean operation.

To increase the efficiency of a dual-fuel gas turbine combustion chamber for an FPSO, the idea of preliminary partial evaporation and mixing of liquid fuel with air in radial-axial swirlers is proposed. This will ensure the necessary emission characteristics of gas turbine engines when operating on light distillate liquid fuels without additional injection of steam or water.

\section{MATHEMATICAL MODELLING}

The modelling of physical and chemical processes in a dual-fuel low-emission combustion chamber for an FPSO is based on the solution of the differential equations of mass, impulse, and energy conservation for the multi-component, turbulent, chemically reacting system [16-18]. A detailed description of the equations and methods of solving them in the case of using gaseous fuel is given in [19-22].

The main equations of the gaseous phase model are as follows [21, 22]:

- the continuity equation

$$
\frac{\partial \rho}{\partial t}+\frac{\partial}{\partial x_{i}}\left(\rho u_{i}\right)=\dot{\rho}^{S},
$$

- the equation of momentum conservation

$$
\begin{aligned}
\frac{\partial}{\partial t}\left(\rho u_{j}\right) & +\frac{\partial}{\partial x_{i}}\left(\rho u_{i} u_{j}\right)=\frac{\partial}{\partial x_{i}}\left[\mu\left(\frac{\partial u_{i}}{\partial x_{j}}+\frac{\partial u_{j}}{\partial x_{i}}\right)\right]-\frac{\partial p}{\partial x_{j}}+ \\
& +\rho g_{i}+\dot{F}^{S}+\frac{\partial}{\partial x_{i}}\left(\rho \overline{u_{i}^{\prime} u_{j}^{\prime}}\right)
\end{aligned}
$$

- the transfer equations for the kinetic energy of turbulence $k$ and the dissipation rate of turbulent energy $\varepsilon$ for the RNG turbulence model [23]:

$$
\begin{gathered}
\frac{\partial}{\partial t}(\rho k)+\frac{\partial}{\partial x_{i}}\left(\rho k u_{i}\right)=\frac{\partial}{\partial x_{j}}\left[\left(\alpha_{k} \mu_{e f f}\right) \frac{\partial k}{\partial x_{j}}\right]+ \\
+G_{k}+G_{b}-\rho \varepsilon-Y_{M}+S_{k}, \\
\frac{\partial}{\partial t}(\rho \varepsilon)+\frac{\partial}{\partial x_{i}}\left(\rho \varepsilon u_{i}\right)=\frac{\partial}{\partial x_{j}}\left[\left(\alpha_{\varepsilon} \mu_{e f f}\right) \frac{\partial \varepsilon}{\partial x_{j}}\right]+ \\
+C_{1 \varepsilon} \frac{\varepsilon}{k}\left(G_{k}+C_{3 \varepsilon} G_{b}\right)-C_{2 \varepsilon} \rho \frac{\varepsilon^{2}}{k}-R_{\varepsilon}+S_{\varepsilon} .
\end{gathered}
$$

- the energy conservation equation

$$
\begin{gathered}
\frac{\partial}{\partial t}\left(\rho h_{0}\right)+\frac{\partial}{\partial x_{i}}\left(\rho u_{i} h_{0}\right)=\frac{\partial}{\partial x_{i}} \frac{k_{m}+k_{t}}{c_{p}}\left[\frac{\partial\left(h_{0}-u^{2} / 2\right)}{\partial x_{i}}-\sum_{j} h_{j} \frac{\partial X_{j}}{\partial x_{i}}\right]- \\
-\frac{\partial}{\partial x_{i}} \sum_{j} h_{j} J_{j i}+\frac{\partial p}{\partial t}-\frac{\partial}{\partial x_{i}}\left(\tau_{i k} u_{k}\right)+S_{h}+\dot{Q}^{S},
\end{gathered}
$$

- the equation for the conservation of chemical components

$$
\frac{\partial}{\partial t}\left(\rho Y_{i}\right)+\frac{\partial}{\partial x_{i}}\left(\rho u_{i} Y_{i}\right)=\frac{\partial}{\partial x_{i}} J_{i}+R_{i}+\dot{\rho}^{S} \delta_{i} .
$$

In Eqs. (1)-(6), $t$ is the time; $x_{i}$ and $x_{j}$ are the coordinates; $\rho, u, \mu, p$, and $g$ are the density, velocity, viscosity, pressure, and gravity acceleration; $\mu_{\text {eff }}$ is the efficient viscosity coefficient; $\alpha_{k}$ and $\alpha_{\varepsilon}$ are the reverse values of the efficient Prandtl number for $k$ and $\varepsilon$, respectively; $\dot{\rho}^{S}, \dot{F}^{S}, \dot{W}^{S}$, and $\dot{Q}^{S}$ are the sources for interaction of the gas and liquid phases; $G_{k}$ is the source describing the generation of turbulent energy; $C_{1}, C_{2}$ and $C_{s}$ are the empirical constants; $h_{0}$ is the stagnation enthalpy; $h_{j}$ is the component's enthalpy; $k_{m}$ and $k_{t}$ are the coefficients of molecular and effective thermal conductivity; $c_{p}$ is the specific heat of the mixture at constant pressure; $\tau_{i k}$ is the shear stress tensor; $J_{j i}$ is the component $j$ flow in the direction $i ; S_{h}$ is the source term from the chemical reaction; $Y_{i}$ is the mass fraction of component $i ; R_{i}$ is the rate of the component's formation or destruction; $J_{i}$ is the diffusion component's flow; and $\delta_{i}$ is the Dirac delta function. 
The net source of chemical species $i$ due to the reaction is computed as the sum of the Arrhenius reaction sources over the $N_{R}$ reactions in which the species participate:

$$
R_{i}=M_{w, i} \sum_{r=1}^{N_{R}} R_{i, r}
$$

where $M_{w, i}$ is the molecular weight of species $i$ and $R_{i, r}$ is the Arrhenius molar rate of creation/destruction of species $i$ in reaction $r$.

Consider the $r$-th reaction written in general form:

$$
\sum_{i=1}^{N} v_{i, r}^{\prime} M_{i} \underset{k_{b, r}}{\stackrel{k_{f, r}}{\Leftrightarrow}} \sum_{i=1}^{N} v_{i, r}^{\prime \prime} M_{i},
$$

where $N$ is the number of chemical species in the system; $v^{\prime}$ is the stoichiometric coefficient for reactant $i$ in reaction $r$ $v_{i, r}^{i, r}$ is the stoichiometric coefficient for product $i$ in reaction $r$; $\mathrm{M}_{i}$ is the symbol denoting species $i ; k_{f, r}$ is the forward rate constant for reaction $r$; and $k_{b, r}$ is the backward rate constant for reaction $r$.

For a non-reversible reaction, the molar rate of creation/ destruction of species $i$ in reaction $r$ is given by

$$
R_{i, r}=\Gamma\left(v_{i, r}^{\prime \prime}-v_{i, r}^{\prime}\right) \cdot\left(k_{f, r} \prod_{j=1}^{N}\left[C_{j, r}\right]^{\left(\eta_{j,+}^{\prime}+\eta_{i, j}^{\prime}\right)}\right),
$$

where $C_{j, r}$ is the molar concentration of species $j$ in reaction $r$; $\eta_{j, r}^{\prime}$ is the rate exponent for reactant species $j$ in reaction $r$; $\eta_{j, r}^{\prime \prime}$ is the rate exponent for product species $j$ in reaction $r$; and $\Gamma$ presents the net effect of third bodies on the reaction rate:

$$
\Gamma=\sum_{j}^{N_{r}} \gamma_{j, r} C_{j},
$$

where $\gamma_{j, r}$ is the third-body efficiency of the $j$-th species in the reaction $r$.

The Eddy Dissipation Concept (EDC) combustion model [24] includes detailed chemical mechanisms in turbulent flows and is applied in the present investigation. It assumes that the reaction occurs in small turbulent structures, called fine scales. The length fraction of the fine scales is modelled as

$$
\xi^{*}=C_{\xi}\left(v \varepsilon / k^{2}\right)^{0.75},
$$

where $C_{\xi}$ is the volume fraction constant and is the kinematic viscosity.

Species are assumed to react in the fine structures over a time scale

$$
\tau^{*}=C_{\tau}(\nu / \varepsilon)^{0.5}
$$

where $C_{\tau}=0.4082$ is the time-scale constant.

Reactions proceed over the time scale $\tau^{*}$, governed by the Arrhenius rates, and are integrated numerically using the ISAT algorithm [25]. The validity of the EDC approach for modelling physicochemical processes is demonstrated for two-phase turbulent swirl liquid spray combustion in a complex gas turbine combustion chamber [26] and for a model gas turbine combustor [27].
Modelling of nitrogen oxides emissions was carried out using transfer equations which include convection, diffusion, formation, and decomposition of $\mathrm{NO}$ and related compounds. The influence of the reaction volume's residence time on the mechanism of nitrogen oxide formation is considered in the convection terms of the defining equations written in the Euler reference system. For thermal and prompt nitrogen oxides, it is necessary to solve the NO transfer equation $[18,21]$ :

$$
\frac{\partial}{\partial t}\left(\rho Y_{\mathrm{NO}}\right)+\nabla \cdot\left(\rho \vec{v} Y_{\mathrm{NO}}\right)=\nabla \cdot\left(\rho D \nabla Y_{\mathrm{NO}}\right)+S_{\mathrm{NO}},
$$

where $\rho$ is the nitrogen oxide density; $Y_{\mathrm{NO}}$ is the NO mass fraction; $D$ is the diffusion coefficient; $\vec{v}$ is the velocity vector; and $S_{\mathrm{NO}}$ is the source term depending on the NO formation mechanism.

To simulate the formation of carbon monoxide and molecular hydrogen in the combustion chamber, it is proposed to use a five-step combustion model: Eqs. (14)-(18). The kinetic mechanism of hydrocarbon $\mathrm{C}_{16} \mathrm{H}_{29}$ (equivalent to light distillate fuel) combustion is as follows:

$$
\begin{gathered}
2 \mathrm{C}_{16} \mathrm{H}_{29}+16 \mathrm{O}_{2} \rightarrow 32 \mathrm{CO}+29 \mathrm{H}_{2} \\
2 \mathrm{H}_{2}+\mathrm{O}_{2} \rightarrow 2 \mathrm{H}_{2} \mathrm{O} \\
2 \mathrm{CO}+\mathrm{O}_{2}-2 \mathrm{CO}_{2} \\
2 \mathrm{H}_{2} \mathrm{O} \rightarrow 2 \mathrm{H}_{2}+\mathrm{O}_{2} \\
2 \mathrm{CO}_{2} \rightarrow 2 \mathrm{CO}+\mathrm{O}_{2}
\end{gathered}
$$

Validation of similar global chemical mechanisms for the conditions of a gas turbine combustion chamber was carried out in a number of works [18, 28, 29].

For calculations of liquid fuel combustion in a low-emission combustion chamber, the Discrete Phase Model (DPM), which calculates the trajectories of motion for individual particles, was selected $[18,30]$.

The model predicts the particle trajectories of the discrete phase by integrating their motion equations written in the Lagrange form $[18,30,31]$ (given only for the $x$-direction):

$$
\frac{d u_{p}}{d t}=F_{D}\left(u-u_{p}\right)+\frac{g_{x}\left(\rho_{p}-\rho\right)}{\rho_{p}}+F_{x}
$$

where $F$ is the additional term that takes into consideration the gas flow acceleration; $F_{D}\left(u-u_{p}\right)$ is the drag force, which is per unit mass of the particle:

$$
F_{D}=\frac{18 \mu}{\rho_{p} d_{p}^{2}} \frac{C_{D} \operatorname{Re}}{24} .
$$

In the above expressions, $u$ is the gas phase velocity; $u_{p}$ is the particle velocity; $\mu$ is the coefficient of the gas phase molecular viscosity; $\rho$ is the gas phase density; $\rho_{p}$ is the particle density; $d_{p}$ is the current particle diameter; Re is the Reynolds number; and $C_{D}$ is the particle drag coefficient. 
The turbulent dispersion of the particles over their averaged trajectory is calculated using statistical methods. The particle distribution over the averaged trajectory is represented as the Gaussian probability density function, whose change is determined by the degree of particle dispersion due to the action of turbulent pulsations. Turbulent dispersion is calculated by integrating the equations of motion of individual particles using instantaneous values of the gas phase velocities in their vicinity.

The inert heating model is used when the droplet temperature is less than the evaporation temperature. To calculate the change in particle temperature over time $T_{p}(t)$, the heat balance equation is used, which takes into consideration convective and radiative heat transfer:

$$
m_{p} c_{p} \frac{d T_{p}}{d t}=h A_{p}\left(T_{\infty}-T_{p}\right)+\varepsilon_{p} A_{p} \sigma\left(\theta_{R}^{4}-T_{p}^{4}\right)
$$

where $m_{p}$ is the mass of the particle; $c_{p}$ is the specific heat of the particle at constant pressure; $A_{p}$ is the particle surface; $T_{\infty}$ is the local gas phase temperature; $h$ is the heat transfer coefficient; $\varepsilon_{p}$ is the particle radiation coefficient; $\sigma$ is the Stefan-Boltzmann constant; and $\theta_{R}$ is the radiation temperature.

The heat transfer coefficient $h$ is calculated using the Ranz and Marshall correlation:

$$
\mathrm{Nu}=\frac{h d_{p}}{k_{\infty}}=2.0+0.6 \operatorname{Re}_{d}^{1 / 2} \operatorname{Pr}^{1 / 3},
$$

where $k_{\infty}$ is the coefficient of thermal conductivity of the gas phase; $\operatorname{Re}_{d}$ is the Reynolds number, which is determined by the droplet diameter and its relative velocity; and Pr is the Prandtl number for the gaseous phase.

The radiation temperature and the incident radiation $G$ are:

$$
\begin{gathered}
\theta_{R}=(\mathrm{G} / 4 \sigma)^{1 / 4} \\
G=\int_{\Omega=4 \pi} I d \Omega,
\end{gathered}
$$

where $I$ is the radiation intensity; $\Omega$ is the solid angle.

The above equations are integrated over time using an approximately linear form, which implies that the temperature of the particles changes rather slowly.

The evaporation pattern is initiated when the particle temperature reaches the evaporation temperature $T_{e v a p}$ and is used as long as the temperature does not exceed the boiling point $T_{b p}$ or until the volatile particle components are completely consumed (in the case of residual fuel combustion).

The equation of particle heat transfer with gas phase during their evaporation takes into consideration the convective and radiative heat flows as well as the process of vaporization:

$m_{p} c_{p} \frac{d T_{p}}{d t}=h A_{p}\left(T_{\infty}-T_{p}\right)+\varepsilon_{p} A_{p} \sigma\left(\theta_{R}^{4}-T_{p}^{4}\right)+\frac{d m_{p}}{d t} h_{f g}$

where $h_{f g}$ is the latent heat of evaporation.

The mass of the particle during evaporation decreases in accordance with the balance equation:

$$
m_{p}(t+\Delta t)=m_{p}(t)-N_{i} A_{p} M_{w, i} \Delta t
$$

where $M_{w, i}$ is the molecular weight of the particle $i$.

The degree of evaporation is determined by the diffusion flow of fuel vapour into the gas phase and is proportional to the gradient of vapour concentrations on the particle surface and in the gas environment:

$$
N_{i}=k_{c}\left(C_{i, S}-C_{i, \infty}\right),
$$

where $N_{i}$ is the molar flow of evaporated substance; $k_{c}$ is the mass transfer coefficient; $C_{i, S}$ is the vapour concentration on the droplet surface; and $C_{i, \infty}$ is the vapour concentration in the gas environment.

When the particle temperature reaches the boiling point, the following equation is used to change its diameter:

$$
-\frac{d\left(d_{p}\right)}{d t}=\frac{2}{\rho_{p} h_{f s}}\left[\frac{2 k_{\infty}\left[1+0.23 \sqrt{\operatorname{Re}_{d}}\right]}{d_{p}}\left(T_{\infty}-T_{p}\right)+\varepsilon_{p} \sigma\left(\theta_{R}^{4}-T_{p}^{4}\right)\right] .
$$

For simplicity, it is assumed that the temperature of the droplet does not change when boiling. The energy required for evaporation is taken into consideration as a source term in the equation for the energy conservation of the gas phase. Liquid evaporation is also a source of chemical component for the gas phase.

\section{EXPERIMENTAL SETUP AND VERIFICATION OF THE MATHEMATICAL MODEL}

A low-emission combustion chamber with partial preliminary mixing of fuel and air for a 25-MW UGT25000 gas turbine engine produced by Zorya-Mashroekt [21, 32] operating on gaseous fuel was chosen as the object of investigation. The combustion chamber has a cannular counterflow structure (Fig. 1), which implements the principle of dry combustion of a partially mixed lean mixture [21]. The main element of such a chamber is a burner device consisting of two radial-axial swirlers of the first and second channels, behind which the annular mixing chambers are located. The proportion of air flowing through the first and second swirlers' channels is approximately 12 and $61 \%$, respectively, of the total air flow through the flame tube. The fuel gas is fed through a series of holes made in the blades of the radial-axial swirlers of the first and second channels.

To verify the results of a three-dimensional mathematical model, experimental measurements of the temperature field at 25 points of the outlet section of the single burner compartment of a gas turbine combustion chamber for seven operating modes were performed (Table 1). The operating modes differed in the inlet parameters of air and fuel and in the distribution of gaseous fuel flow rates between the outer and inner swirlers' channels [21]. Due to the features of the used test bench, the operating pressure in the compartment did not exceed $0.15 \mathrm{MPa}$ in all operating modes. 


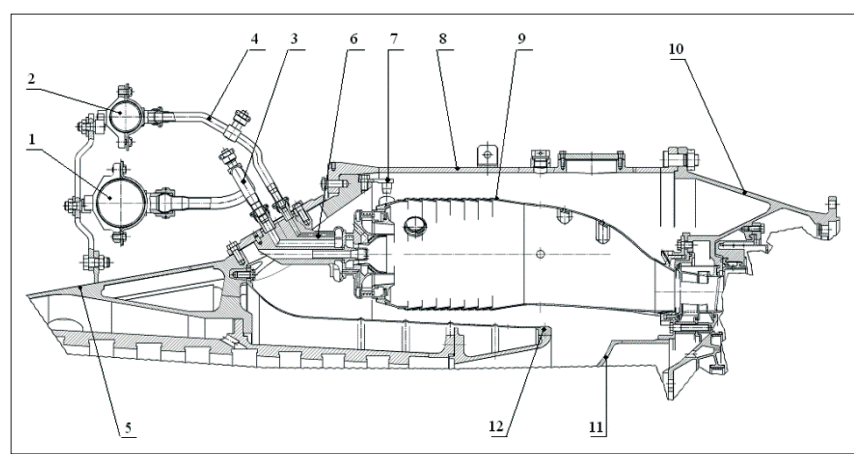

Fig. 1. Low-emission gas turbine combustion chamber: 1, 2-collectors of the first and second channels; 3, 4-delivery pipes of the first and second channels; 5 - compressor casing; 6 - burner; 7 - holder; 8 - combustor casing;

9 - flame tube; 10 - load-carrying body; 11 -diffuser; 12 - inner casing

Note that operating modes 3 and 6 approximately correspond to the nominal mode of the gas turbine engine according to the gas temperature at the turbine inlet.

Tab. 1. Operating modes of bench experiment

\begin{tabular}{|c|c|c|c|c|}
\hline $\begin{array}{c}\text { Mode } \\
\text { number }\end{array}$ & $\begin{array}{c}\text { Air flow } \\
\text { through the } \\
\text { compartment, } \\
\mathrm{kg} / \mathrm{s}\end{array}$ & $\begin{array}{c}\text { Inlet air } \\
\text { temperature, } \\
\mathrm{K}\end{array}$ & $\begin{array}{c}\text { Total fuel } \\
\text { mass flow } \\
\text { rate } G_{f}, \mathrm{~kg} / \mathrm{h}\end{array}$ & $\begin{array}{c}\text { Fuel } \\
\text { temperature, } \\
\mathrm{K}\end{array}$ \\
\hline 1 & 0.395 & 389 & 4.8 & 286.0 \\
\hline 2 & 0.313 & 624 & 18.8 & 287.2 \\
\hline 3 & 0.318 & 626 & 22.6 & 287.5 \\
\hline 4 & 0.315 & 628 & 25.6 & 287.6 \\
\hline 5 & 0.315 & 627 & 25.0 & 287.5 \\
\hline 6 & 0.316 & 605 & 20.9 & 287.5 \\
\hline 7 & 0.327 & 667 & 27.9 & 288.0 \\
\hline
\end{tabular}

Figure $=2$ shows a comparison of the measured and calculated gas temperatures at the outlet of the low-emission combustion chamber [21], from which it can be concluded that that using three-dimensional methodology it is possible to reliably predict the exhaust gas temperature distribution for a wide range of operating modes.

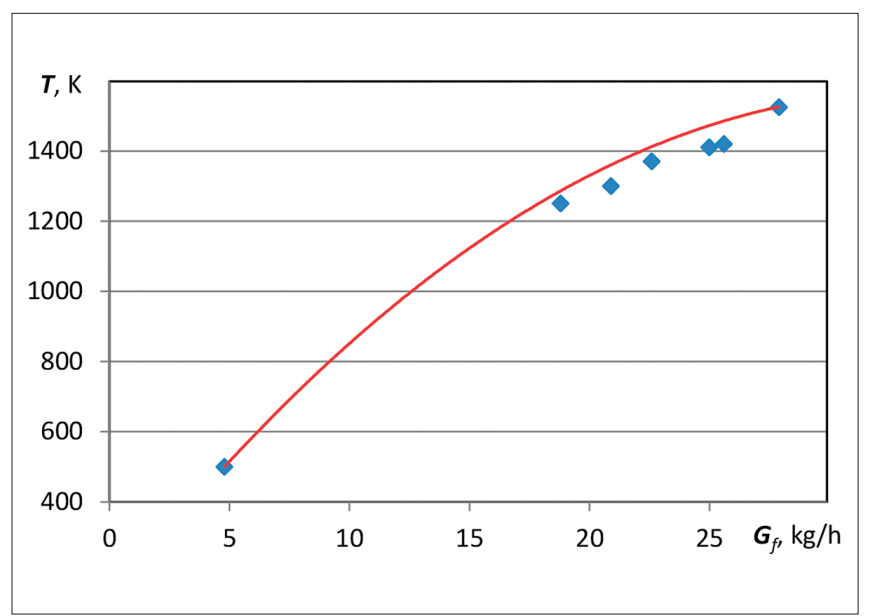

Fig. 2. The distribution of the average temperature at the combustion chamber's outlet: - experiment; - calculation
The measured and calculated values of the nitrogen oxide emission for the seven test modes are presented in Fig. 3. A good correlation of the data indicates adequacy of the mathematical model of the formation/decomposition of nitrogen oxides.

Note that the investigation of the aerodynamic flow structure in a low-emission gas turbine combustion chamber under isothermal and non-isothermal conditions confirms the reliability of the proposed mathematical model, its adequacy for physical processes, and the qualitative and quantitative agreement of the experimental and calculated data, which makes it possible to use it for predicting the parameters of a dual-fuel gas turbine combustion chamber for an FPSO.

\section{INVESTIGATION OF CHARACTERISTICS OF WORKING PROCESSES IN A DUAL-FUEL LOW-EMISSION COMBUSTION CHAMBER}

For a 1/16 part of a low-emission combustion chamber of a 25-MW gas turbine engine, the finite-difference mesh consists of 2.7 million tetrahedrons. The following initial conditions are accepted: an air temperature at the diffusor inlet of $770 \mathrm{~K}$, a pressure of $20.523 \mathrm{MPa}$, an air flow rate of $4.355 \mathrm{~kg} / \mathrm{s}$, and a total liquid fuel consumption through the fuel supply pipes of $359.64 \mathrm{~kg} / \mathrm{h}$. These parameters correspond to the nominal operating mode of a $25-\mathrm{MW}$ gas turbine engine. To simplify the calculations, the flame tube walls were taken as adiabatic. Typical root mean square (RSM) residuals to establish the solution convergence are about 1e-4.

Four methods of supplying liquid fuel to the flame tube's burner are considered:

1) a centrifugal method, in which $100 \%$ of the fuel is fed through a central centrifugal nozzle (Fig. 4a);

2) an axial method, in which $95 \%$ of the fuel $(0.09495 \mathrm{~kg} / \mathrm{s})$ is fed axially through 15 tubes located in the outer swirler and $5 \%$ of the fuel $(0.00495 \mathrm{~kg} / \mathrm{s})$ is fed axially through 15 tubes located in the inner swirler (Fig. 4b);

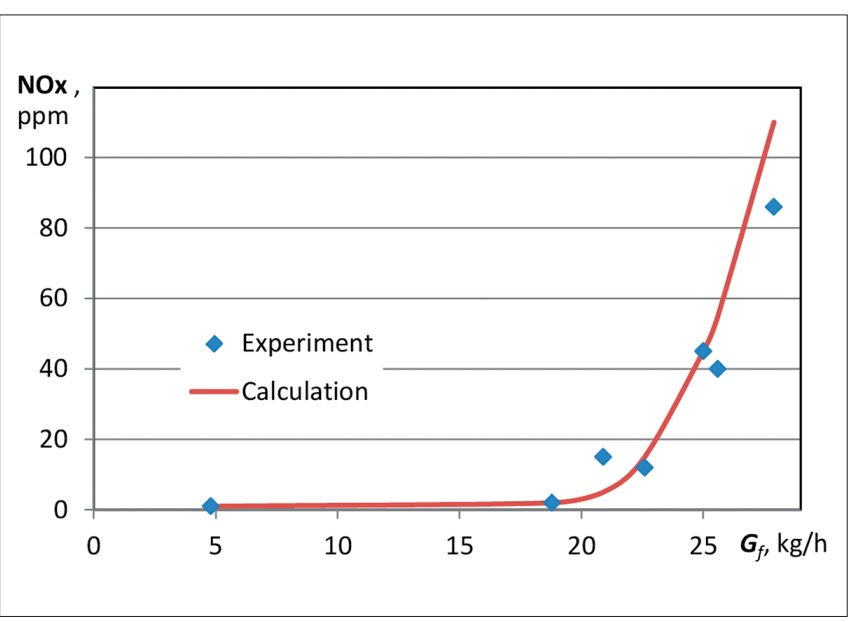

Fig. 3. Emission of nitrogen oxides depending on gaseous fuel mass flow rate 
3) a combined method (radial-centrifugal), in which $92 \%$ of the fuel $(0.09193545 \mathrm{~kg} / \mathrm{s})$ is fed through the outer swirler radially, $4.8 \%$ of the fuel $(0.0048375 \mathrm{~kg} / \mathrm{s})$ is fed through the inner swirler radially, and $3.2 \%$ of the fuel $(0.003225 \mathrm{~kg} / \mathrm{s})$ is fed through the central centrifugal nozzle (Fig. 4c); and

4) a radial method, in which $95 \%$ of the fuel is fed radially through the outer swirler and 5\% of the fuel is fed radially through the inner swirler (Fig. 4d).

In most cases, the modelling uses a "single" fuel injection method: a fuel stream flows through a series of smalldiameter single tubes that are fed into the radial-axial swirlers. The initial diameters of the fuel droplets for the cases with the central centrifugal nozzle are based on the Rosin-Rammler distribution (from 5 to $75 \mu \mathrm{m}$ ); for all other cases (axial and radial supply of liquid fuel) the starting average diameter is taken as $50 \mu \mathrm{m}$. The accepted parameters of distillate fuel spraying are an initial droplet flow velocity of $50 \mathrm{~m} / \mathrm{s}$ and a fuel spray angle of $70^{\circ}$. The computer program ANSYS Fluent is used for calculations.

Figure 4 shows liquid particle traces in the longitudinal section of the flame tube, depending on the supply method, taking into consideration the features of mixing the fuel with the oxidizer in the channels of the radial-axial swirlers. Centrifugal and axial methods of liquid fuel supply (1 and 2) are characterized by the longest track lines, and the process of droplet evaporation is completed only in the area of the third shell of the flame tube. This indicates the unsatisfactory quality of the processes of droplet heating, evaporation, and mixing of the fuel vapour with the oxidizer.

This is confirmed by the data in Fig. 5, which shows the temperature contours in the longitudinal section of the flame tube, depending on the method of fuel supply. When the centrifugal supply method (1) is used, the fuel torch extends almost to the flame tube's outlet; the liquid fuel does not completely burn out, causing extremely high temperature-field non-uniformity at the outlet (Table 1). When the axial fuel supply method (2) is used, the droplets are concentrated in the area of the flame tube walls and burn down in these regions, which leads to a sharp increase in the temperature of the flame tube's shells and their possible burnout. Methods 3 and 4 lack the aforementioned disadvantages, which results in significantly more efficient liquid fuel combustion.

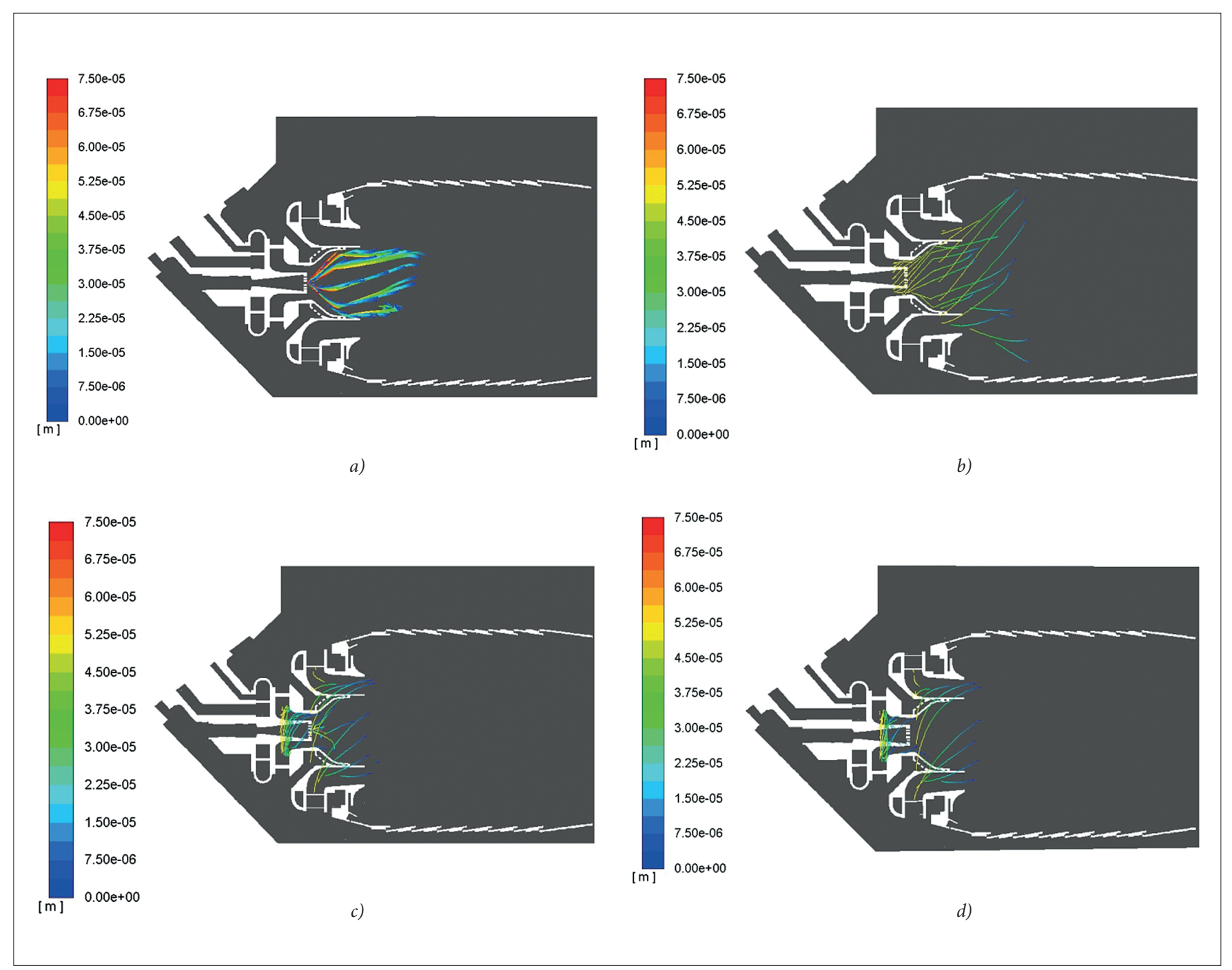

Fig. 4. Liquid particle traces coloured by particle diameter $(m)$ with different supply methods: (a) 1 ; (b) 2; (c) 3; (d) 4 


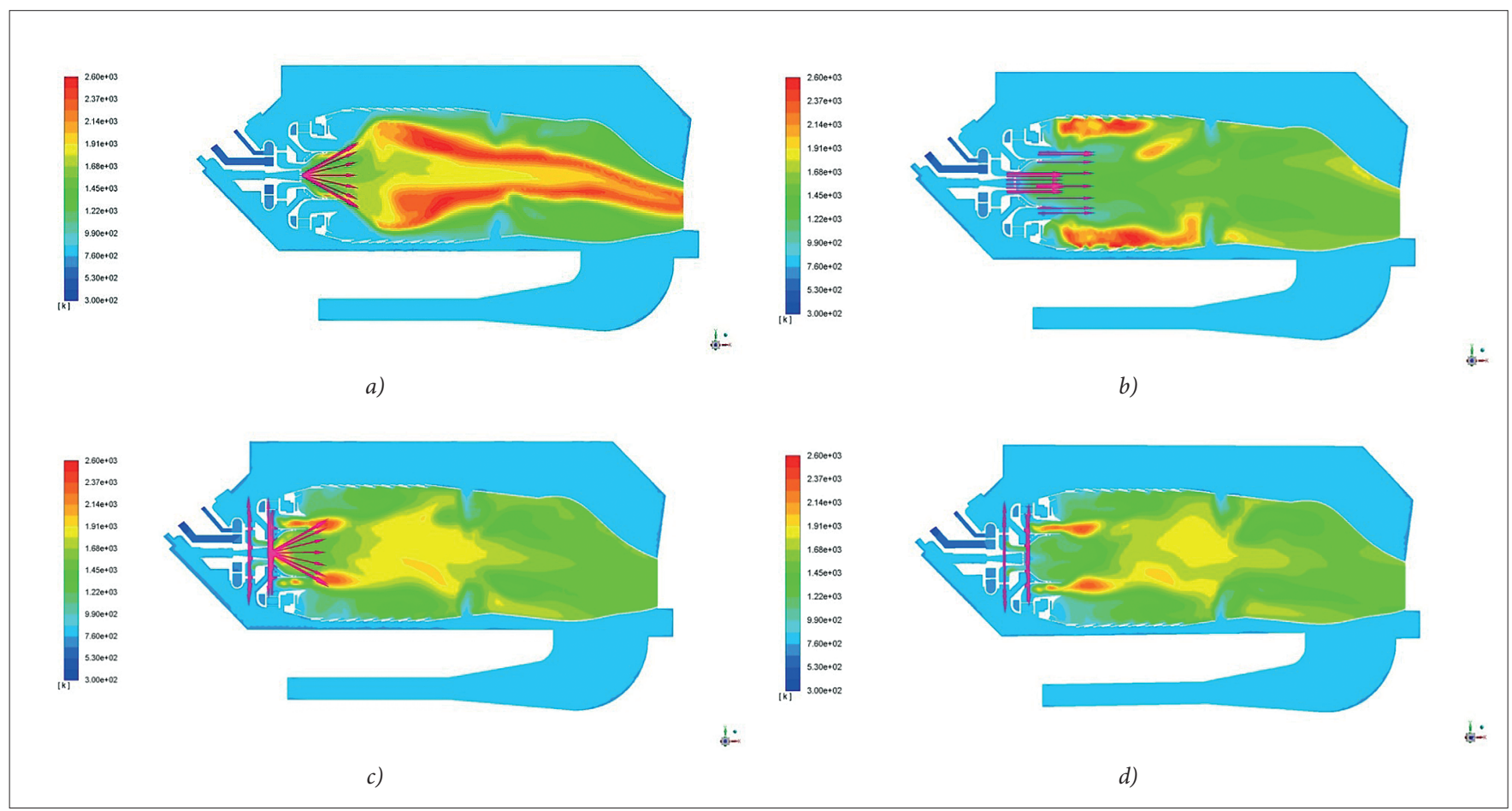

Fig. 5. Distribution of gas temperatures along the flame tube with different fuel supply methods: (a) 1 ; (b) 2; (c) 3; (d) 4

It should be noted that the liquid fuel supply into the primary zone of the low-emission combustion chamber with a high air-excess coefficient can lead to a deterioration of the conditions of flame stabilization, pulsations, and even the possible extinction of the torch. To increase the stability of liquid fuel combustion under dual-fuel combustion chamber conditions, it is advisable to use plasma-chemical combustion intensifiers $[33,34]$, which, as shown in $[16,18]$, significantly extend the flame propagation limits and stability under conditions of very lean fuel-air mixtures.

Figure 6 shows the contours of volume concentrations of nitrogen oxides in the flame tube's longitudinal section, which are determined by the appropriate temperature distribution since the main factor is the thermal mechanism of nitrogen oxides formation.
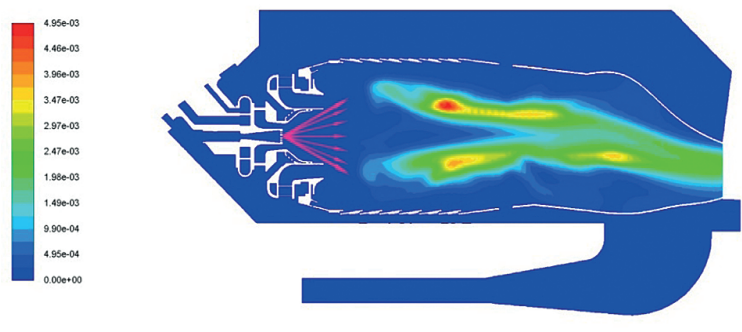

a)

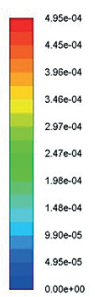

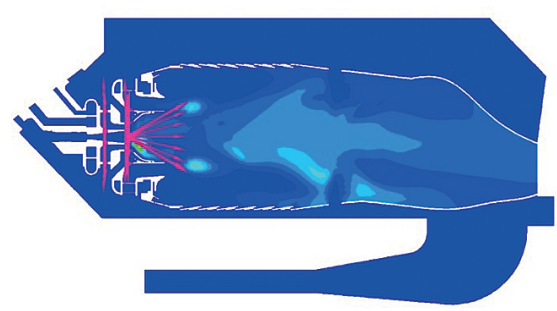

c)
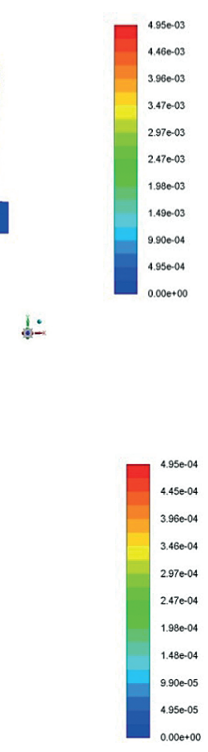

a.

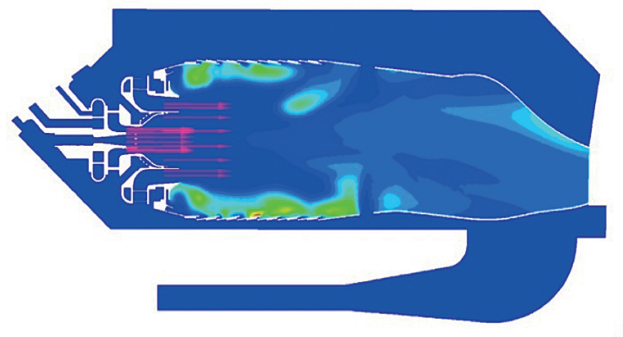

b)

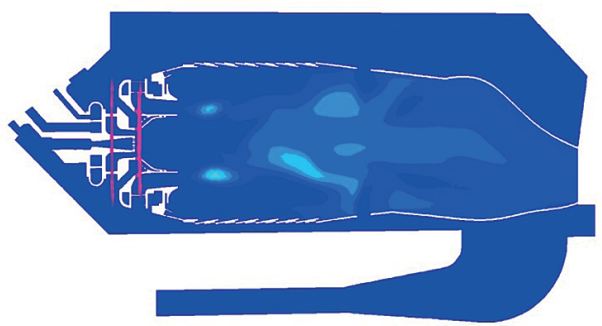

d)

Fig. 6. Distribution of NO mole fractions with different fuel supply methods: (a) 1; (b) 2; (c) 3; (d) 4 
Liquid fuel supply methods 3 and 4 with a lower maximum combustion temperature are also determined by lower levels of nitrogen oxide emissions.

Figure 7 shows the calculated dependencies of $\mathrm{NO}$ and $\mathrm{CO}$ emissions (at $15 \% \mathrm{O}_{2}$, dry basis) and the overall temperaturefield non-uniformity $\delta$ at the exit combustion chamber section on the fuel supply methods.

It should be noted that the coefficient of the overall temperature-field non-uniformity is determined by the formula

$$
\delta=\frac{T_{\max }-T_{\min }}{T_{a v}},
$$

where $T_{\max }, T_{\min }$, and $T_{a v}$ are the maximum, minimum, and average gas temperature in the outlet flame tube's section.
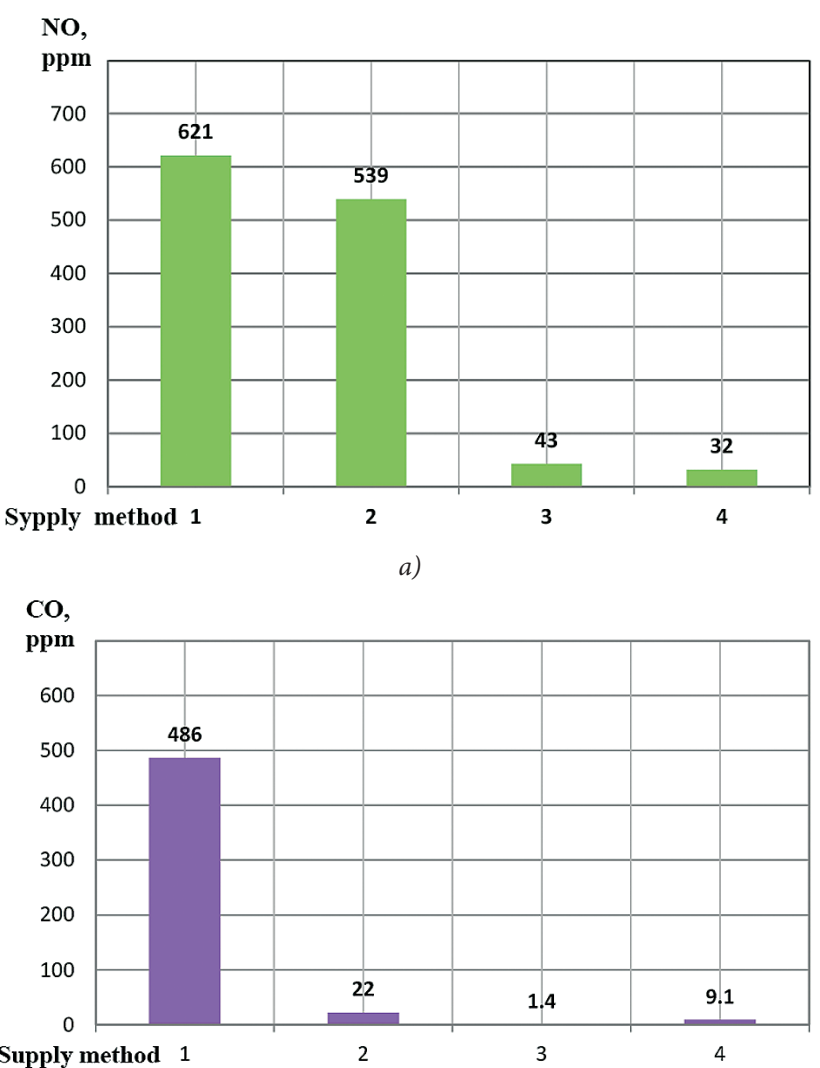

b)

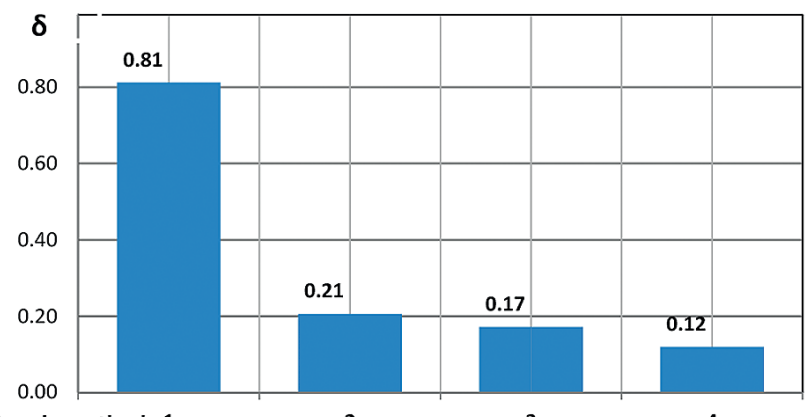

Supply method 1

c)

Fig. 7. Combustion chamber's outlet parameters with different fuel supply methods: (a), (b) NO and CO emission at $15 \% \mathrm{O}_{2}$, dry basis; (c) temperature-field non-uniformity
For the most effective radial fuel supply method, the effect of the liquid fuel outflow velocities on the characteristics of a dual-fuel combustion chamber was also analysed. There is a close connection between temperature distribution (Fig. 8), nitrogen oxides concentrations (Fig. 9), turbulence, and flow patterns.

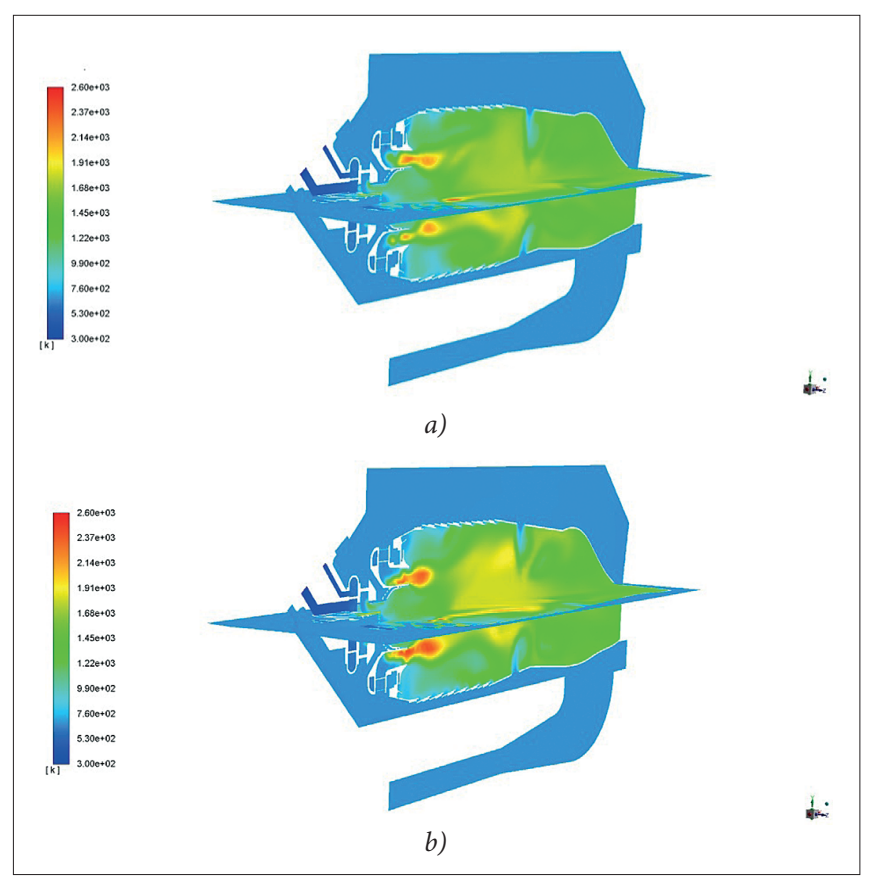

Fig. 8. Temperature contours (K) at different fuel outflow velocities: (a) $5 \mathrm{~m} / \mathrm{s}$; (b) $50 \mathrm{~m} / \mathrm{s}$

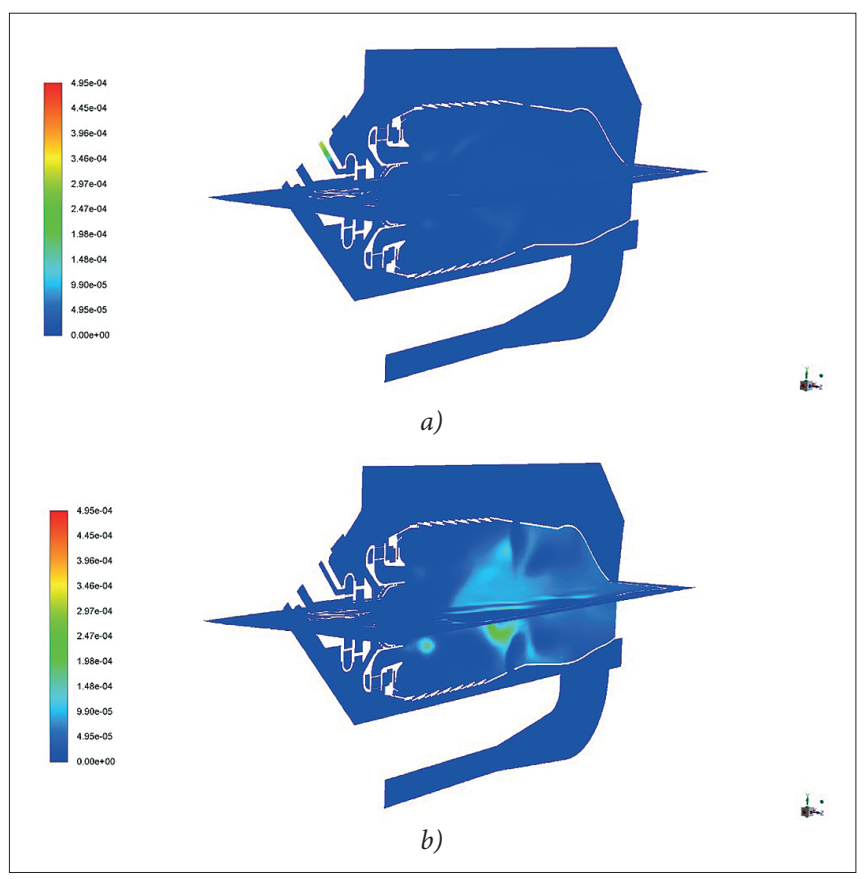

Fig. 9. Contours of NO mole fractions at different fuel outflow velocities: (a) $5 \mathrm{~m} / \mathrm{s}$; (b) $50 \mathrm{~m} / \mathrm{s}$

The dependence of nitrogen oxides emissions on the fuel outflow velocity $V_{\text {fout }}$ is presented in Fig. 10. Improvement in the conditions of mixing and better homogenization of the mixture of evaporated fuel and air in the outer and inner 
swirlers' channels with a decrease in the fuel outflow velocities lead to a decrease in the rate of nitrogen oxides formation. In addition, growth in the fuel outflow velocities shifts the high-temperature zone to the secondary air supply holes (Fig. 9) and causes higher concentrations of nitrogen oxides in these areas, which are closer to the exit section of the flame tube.

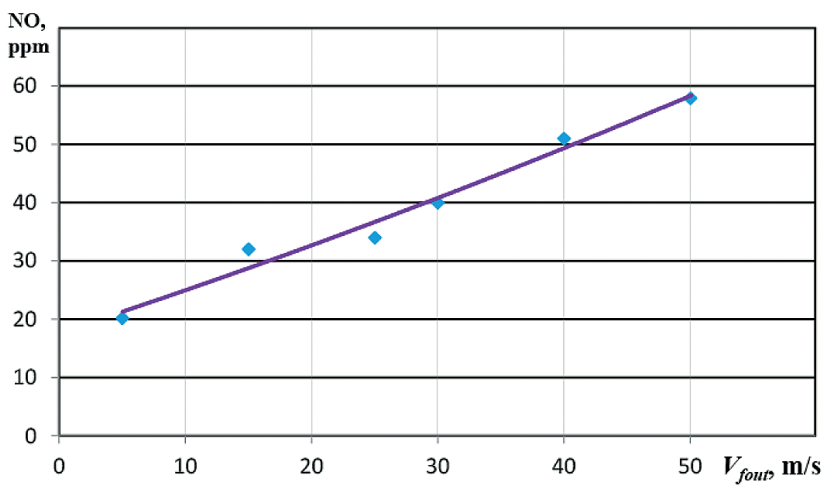

Fig. 10. Influence of nitrogen oxides emission (at 15\% $\mathrm{O}_{2}$, dry basis) on the fuel outflow velocities

Note that with the radial liquid fuel supply, the processes of droplet evaporation and mixing of vapours with air occur quite quickly. The combustion process even begins inside the swirlers' channels, which can lead to increases in the temperature of the metal surfaces and carbon deposition and decrease the reliability of the flame tube operation in general. To solve this problem, in the next investigations, it is planned to redistribute the amount of air entering the swirlers' channels and the flame tube mixer and to partially change the design of the front device.

It is known that gas turbine engines (including combined cycle gas turbines) using light and middle distillates as liquid fuels in the European Union should be subject to emission limit values of $90 \mathrm{mg} / \mathrm{nm}^{3}$ ( 44 ppm) for NOx and $100 \mathrm{mg} / \mathrm{nm}^{3}$ $(\sim 80 \mathrm{ppm})$ for $\mathrm{CO}$, and those using natural gas as fuel should be subject to emission limit values of $50 \mathrm{mg} / \mathrm{nm}_{3}(\sim 25 \mathrm{ppm})$ for $\mathrm{NO}_{\mathrm{x}}$ and $100 \mathrm{mg} / \mathrm{nm}^{3}$ ( 81 ppm) for CO [35].

The radial method of liquid fuel supply to a dual-fuel gas turbine combustion chamber for an FPSO energy module, in which $95 \%$ of the fuel is fed radially through the outer swirler and $5 \%$ of the fuel is fed radially through the inner swirler, provides calculated NOx and $\mathrm{CO}$ emissions (32 and 9.1 ppm) that satisfy international environmental requirements.

\section{FINAL CONCLUSIONS}

To implement the principle of low-emission combustion of liquid distillate fuel in a dual-fuel gas turbine combustion chamber without additional injection of water or steam, the idea of preliminary mixing of the evaporated fuel in the outer and inner channels of radial-axial swirlers is proposed. The performed three-dimensional calculations of the aerodynamic and emission parameters of the cannular counterflow combustion chamber allow us to draw the following conclusions.
1. To increase the efficiency of the working processes in a dual-fuel gas turbine chamber for an FPSO it is proposed to use the idea of pre-mixing of liquid fuel with air in radial-axial swirlers.

2. The developed three-dimensional mathematical model of liquid fuel burning in a dual-fuel low emission combustion chamber contains the following equations: continuity, impulse, energy conservation, and transfer of chemical components, taking into consideration dissipation of vortices, formation, and decomposition of nitrogen oxides in interaction with the discrete phase.

3. The results of three-dimensional mathematical modelling confirmed the feasibility of the radial liquid fuel method of supply into the swirlers' channels in a low-emission gas turbine combustion chamber for an FPSO and its advantages over the traditional centrifugal fuel supply method.

4. For the radial supply method, the calculated indexes of nitrogen oxide $\mathrm{NO}$ and carbon monoxide $\mathrm{CO}$ emissions in the outlet section of the flame tube are 32 and 9.1 ppm respectively (at $15 \% \mathrm{O}_{2}$, dry basis), which satisfy the current emission requirements for gas turbine engines. The radial liquid fuel supply method has the minimum coefficient of the overall temperature-field non-uniformity in the outlet section (0.12).

5. Increasing the fuel outflow velocities when feeding liquid fuel into the channels of the inner and outer flame tube's swirlers from 5 to $50 \mathrm{~m} / \mathrm{s}$ increases the estimated nitrogen oxides emissions from 20 to $58 \mathrm{ppm}$.

\section{REFERENCES}

1. Offshore Technology (2018): Report:55 FPSOstostartoperations by 2022. Retrieved from https://www.offshore-technology. com/news/report-55-fpsos-start-operations-2022/.

2. Offshore Magazine (2002): Leadon FPSO delivered on time, complete, within budget. Retrieved from https:// www.offshore-mag.com/production/article/16759844/ leadon-fpso-delivered-on-time-complete-within-budget.

3. ENI (2016): Block 15-06 East Hub Development Project. Retrieved from https://www.eni.com/docs/en_IT/enicom/ publications-archive/publications/brochures-booklets/ countries/brochure_eni_angola_ese_web.pdf.

4. Aker Floating Production (2009): FPSO Dhirubhai-1. Retrieved from http://www.akerfloatingproduction.com/s. cfm/3-12/FPSO-Dhirubhai-1-Operation.

5. Cherednichenko O., Serbin S., Dzida M. (2019): Application of Thermo-Chemical Technologies for Conversion of Associated Gas in Diesel-Gas Turbine Installations for Oil and Gas Floating Units. Polish Maritime Research, 3(103), Vol. 26, 181-187. 
6. Cherednichenko O., Serbin S., Dzida M. (2019): Investigation of the Combustion Process in the Gas Turbine Module of an FPSO Operating on Associated Gas Conversion Products. Polish Maritime Research, 4(104), Vol. 26, 149-156.

7. Domachowski Z., Dzida M. (2019): Applicability of Inlet Air Fogging to Marine Gas Turbine. Polish Maritime Research, 1(101), Vol. 26, 15-19.

8. Burunsuz K.S., Kuklinovsky V.V., Serbin S.I. (2019): Investigations of the Emission Characteristics of a Gas Turbine Combustor with Water Steam Injection. Refrigeration Engineering and Technology, Vol. 55(2), 77-83.

9. Lindman O., Andersson M., Persson M., Munktell E. (2014): Development of a Liquid Fuel Combustion System for SGT-750. In ASME Turbo Expo 2014: Turbine Technical Conference and Exposition. American Society of Mechanical Engineers Digital Collection.

10. Malte P.C., Pratt D.T. (1975): Measurement of Atomic Oxygen and Nitrogen Oxides in Jet-Stirred Combustion. In Symposium (International) on Combustion, Vol. 15(1), 1061-1070.

11. Stöhr M., Boxx I., Carter C.D., Meier W. (2012): Experimental Study of Vortex-flame Interaction in a Gas Turbine Model Combustor. Combustion and Flame, Vol. 159, 2636-2649.

12. Aleiferis P.G., Serras-Pereira J., Romunde Z., Caine J., Wirth M. (2010): Mechanisms of Spray Formation and Combustion from a Multi-Hole Injector with E85 and Gasoline. Combustion and Flame, Vol. 157(4), 735-756.

13. Hertel M., Tartsch D., Sattelmayer S. (2019): Ignition of Diesel Pilot Fuel in Dual-Fuel Engines. Journal of Engineering for Gas Turbines and Power, doi: 141.10.1115/1.4043485.

14. Ibrahim I.A., Shabaan M.M., Shehata M.A., Farag T.M. (2014): Investigation of Dual-Fuel Combustion Characteristics inside a Gas Turbine. Combustor International Conference on Machine Learning, Electrical and Mechanical Engineering (ICMLEME'2014). Dubai (UAE). Retrieved from: http://iieng. org/images/proceedings_pdf/2853E0114035.pdf.

15. Kurji H. (2017): Fuel Flexibility with Low Emissions for Gas Turbine Engines, $\mathrm{PhD}$ thesis, Cardiff University.

16. Matveev I., Serbin S., Mostipanenko A. (2007): Numerical Optimization of the "Tornado" Combustor Aerodynamic Parameters. Collection of Technical Papers - 45th AIAA Aerospace Sciences Meeting, Reno, Nevada, AIAA 2007-391, Vol. 7, 4744-4755.

17. Matveev I.B., Serbin S.I., Vilkul V.V., Goncharova N.A. (2015): Synthesis Gas Afterburner Based on an Injector Type PlasmaAssisted Combustion System. IEEE Transactions on Plasma Science, Vol. 43(12), 3974-3978.
18. Serbin S.I. (1998): Modeling and Experimental Study of Operation Process in a Gas Turbine Combustor with a Plasma-Chemical Element. Combustion Science and Technology, Vol. 139, 137-158.

19. Matveev I., Matveeva S., Serbin S. (2007): Design and Preliminary Result of the Plasma Assisted Tornado Combustor. 43rd AIAA/ASME/SAE/ASEE Joint Propulsion Conference, Collection of Technical Papers, Cincinnati, OH, AIAA 2007 5628, Vol. 6, 6091-6098.

20. Matveev I., Serbin S. (2006): Experimental and Numerical Definition of the Reverse Vortex Combustor Parameters. 44th AIAA Aerospace Sciences Meeting and Exhibit, Reno, Nevada, AIAA-2006-0551, 1-12.

21. Serbin, S.I., Matveev, I.B., Mostipanenko, G.B. (2011): Investigations of the Working Process in a "Lean-Burn" Gas Turbine Combustor with Plasma Assistance. IEEE Trans. Plasma Sci., Vol. 39(12), 3331-3335.

22. Launder B.E., Spalding D.B. (1972): Lectures in Mathematical Models of Turbulence. London: Academic Press, 327.

23. Choudhury D. (1993): Introduction to the Renormalization Group Method and Turbulence Modeling. Fluent Inc. Technical Memorandum TM-107.

24. Magnussen B.F. (1981): On the Structure of Turbulence and a Generalized Eddy Dissipation Concept for Chemical Reaction in Turbulent Flow. Nineteenth AIAA Meeting, St. Louis, 1-7.

25. Pope S.B. (1997): Computationally efficient implementation of combustion chemistry using in-situ adaptive tabulation. Combustion Theory and Modeling, Vol. 1, 41-63.

26. Wang F., Huang Y., Deng T. (2009): Gas Turbine Combustor Simulation with Various Turbulent Combustion Models. Proceedings of ASME Turbo Expo 2009: Power for Land, Sea and Air GT2009, 1-11.

27. Benim A.C., Iqbal S., Meier W., Joos F., Wiedermann A. (2017): Numerical Investigation of Turbulent Swirling Flames with Validation in a Gas Turbine Model Combustor. Applied Thermal Engineering, Vol. 110(2), 202-212.

28. Abou-Taouk A., Sigfrid I.R., Whiddon R., Eriksson L.E. (2012): A Four-Step Global Reaction Mechanism for CFD Simulations of Flexi-Fuel Burner for Gas Turbines. Proceedings of the 17th International Symposium on Turbulence, Heat and Mass Transfer Palermo, Italy, 1-12.

29. Novosselov I.V., Malte P.C. (2007): Development and Application of an Eight-Step Global Mechanism for CFD and CRN Simulations of Lean-Premixed Combustors. Proceedings of GT2007 ASME Turbo Expo 2007: Power for Land, Sea and Air, 1-11. 
30. Faeth G.M. (1979): Spray Combustion Models: A Review, AIAA Paper (293), 1-18.

31. James S., Anand M., Pope S. (2002): The Lagrangian PDF Transport Method for Simulations of Gas Turbine Combustor Flows. In 38th AIAA/ASME/SAE/ASEE Joint Propulsion Conference \& Exhibit, 4017.

32. Romanovsky G.F., Serbin S.I., Patlaychuk V.M. (2005): Modern Gas Turbine Units of Russia and Ukraine. Vol. 1, Mikolayiv: NUK, 344 (in Ukrainian).

33. Gatsenko N.A., Serbin S.I. (1995): Arc Plasmatrons for Burning Fuel in Industrial Installations. Glass and Ceramics, Vol. 51(11/12), 383-386.

34. Serbin S.I., Matveev I.B., Goncharova N.A. (2014): Plasma Assisted Reforming of Natural Gas for GTL. Part I. IEEE Transactions on Plasma Science, Vol. 42(12), 3896-3900.

35. Directive 2010/75/EU of the European Parliament and of the Council of 24 November on Industrial Emissions (Integrated Pollution Prevention and Control) (2010): Official Journal of the European Union. Retrieved from https://eur-lex.europa. eu/legal-content/EN/TXT/?uri=CELEX\%3A32010L0075.

\section{CONTACT WITH THE AUTHORS}

\author{
Serhiy Serbin \\ e-mail:serbin1958@gmail.com
}

Admiral Makarov National University of Shipbuilding Geroes of Ukraine Ave., 9, 54025 Mikolayiv

\section{UKRAINE}

\section{Badri Diasamidze}

e-mail:badri.diasamidze@nuos.edu.ua Admiral Makarov National University of Shipbuilding Geroes of Ukraine Ave., 9, 54025 Mikolayiv

\section{UKRAINE}

\section{Marek Dzida}

e-mail:dzida@pg.edu.pl Gdańsk University of Technology 11/12 Gabriela Narutowicza Street, 80-233 Gdańsk

\section{Poland}

